\title{
BIOMASS ESTIMATION USING VERTICAL FOREST STRUCTURE FROM SAR TOMOGRAGHY: A CASE STUDY IN CANADIAN BOREAL FOREST.
}

\author{
E. Renaudin ${ }^{\text {a, } *}$, B. Mercer ${ }^{\text {a }}$, Q. Zhang ${ }^{\text {b }}$, M.J. Collins ${ }^{\text {a }}$ \\ ${ }^{a}$ University of Calgary, University Drive NW, Calgary, AB, Canada T2N 1N4 \\ (erwan.renaudin,mjcollins)@ucalgary.ca - bryanm@telus.net \\ ${ }^{\mathrm{b}}$ Intermap Technologies Corp., \#500, 635 - 6th Avenue SW, Calgary, AB, T2P 0T5 - qzhang@intermap.com
}

Commission VIII/7

KEY WORDS: POLInSAR, Tomography, Polarimetry, Interferometry, Forestry, Structure, Biomass

\begin{abstract}
:
A major goal of current research is to address temporal climatic variations that are related to $\mathrm{CO} 2$ emissions. A significant portion of these emissions are due to forest destruction and the resulting conversion of biomass to CO2. As $30 \%$ of the earth's landmass is forest-covered, it is important to understand the biomass content with better estimates than are currently available. This research has addressed the determination of forest biomass in a Northern Alberta forest site, using novel techniques known as POLInSAR (Polarimetry Interferometry SAR) to study the 3D vegetated structure of forests through using an L-Band single-pass airborne system. Results of this study indicate strong relation between vertical structure and above ground biomass. In this paper we show the preliminary results of the work including the resulting tomographic expression of the test forest area.
\end{abstract}

\section{INTRODUCTION}

The study of $\mathrm{CO} 2$ emissions into the atmosphere and their impact on climate change are of global interest. The destruction of forests makes a significant contribution to the total (UNDG, 2008) and there is a corresponding interest in improving the accuracy of forest biomass estimates (Houghton et al., 2009) in order to provide baseline information for subsequent monitoring and for mitigation purposes. Remote sensing techniques applied to date, including both optical and radar backscatter approaches, suffer from saturation effects at higher biomass levels (Dong, et al., 2003, Le Toan et al., 1992; Beaudoin et al., 1994; Lefsky et al., 2005; Leckie and Ranson, 1998). In this paper we describe results from an approach involving Polarimetric InSAR (POLInSAR) to extract tomographic images of forest canopy from which biomass estimates can be inferred (Cloude, 2006A). Previous work has shown that tree height and ground elevation can be obtained from L-Band POLInSAR methods and that tree height is a good proxy, through an allometric relationship, to biomass at least for homogeneous forest types (Mette et al., 2004A, 2004B). However the combination of POLInSAR with tomography is intended to address the problem of biomass determination when the forest contains mixed species.

The vertical profiles of forest canopy density (which are represented by the variation of backscatter signal along the vertical) are potentially strong indicators of forest Above Ground Biomass (ABG). Since the radar cross-section observed for a given pixel is the sum or integral of contributions from all scatterers at the same range, encompassing all heights, the information about vertical structure is lost. While POLInSAR techniques allow the height and ground elevations to be estimated, they do not recover the forest structure directly. The virtue of the tomographic approach (Treuhaft et al., 2000; Cloude, 2006A; Hajnsek et al., 2009) is that a threedimensional image of the canopy can be obtained. However, 'standard' tomography generally requires multiple baselines created from multiple passes and hence increased operational costs, for airborne systems at least. To overcome those limitations a recently proposed method (Cloude, 2006A, 2006B, 2009), named Polarisation Coherence Tomography (PCT) has been proposed to solve estimation of the vertical distribution of scattering, with the use of few baselines (one to three). Indirectly, the recovery of biomass within the vertical layers is derived from that vertical profile.

In this paper we tackle the problem of generating those profiles or tomograms to highlight the possible interactions with biomass content.

In section 2, we review the basic elements of PCT including the ultimate goal of extracting forest biomass information; in section 3 we summarize the data set and the system from which it was derived; preliminary results in the form of the derived PCT profiles or tomograms are presented in section 4 with conclusions and follow-on plans summarized in section 5 .

\section{POLARIZATION COHERENCE TOMOGRAPHY}

\subsection{Polarization Coherence Tomography}

An underlying assumption of many approaches, including PCT, is that the forest may be represented by a slab containing a random distribution of scatterers, horizontally homogeneous in their properties, but with backscatter sources distributed in the vertical according to a structure function $f(z)$ where $z$ is the vertical dimension with respect to an impermeable ground surface (Papathanassiou and Cloude, 2003).

This is referred to as the Random Volume Over Ground (RVoG) model The complex coherence, $\tilde{\gamma}$ which is the

\footnotetext{
* Corresponding author.
} 
normalised coherent sum of all contributions, can be formulated for a random distribution of scatterers, as shown in (1), where $\mathrm{s}_{1}$ and $s_{2}$ are the complex signals received at either end of the interferometric baseline, * represents the complex conjugate and $\langle\ldots\rangle$ is the expectation, in practise replaced by an averaging operation.

$$
\tilde{\gamma}=\frac{\left\langle s_{1} s_{2}^{*}\right\rangle}{\sqrt{\left\langle s_{1} s_{* 1}^{*}\right\rangle\left\langle s_{2} s_{2}^{*}\right\rangle}}=e^{i k_{z} z_{0}} \frac{\int_{0}^{h_{v}} f\left(z^{\prime}\right) e^{j k_{z} z^{\prime}} d z^{\prime}}{\int_{0}^{h_{v}} f\left(z^{\prime}\right) d z^{\prime}}=e^{j k_{z} z_{0}}|\tilde{\gamma}| e^{j \arg (\tilde{\gamma})},
$$

with $0 \leq|\tilde{\gamma}| \leq 1$.

In practice, the upper bound of integration is at $z=z_{0}+h_{v}$ where the lower bound is at the reference datum, $z=z_{0}$. The interferometer is then measuring a composite complex signal given by the weighted sum of contributions (taking into account phase). Before estimating the height using the phase to height relation $\phi=k_{z} \cdot h_{v}$, the sensitivity of the interferometers to height variation has to be defined using the vertical wavenumber factor $k_{z}$ (Bamler, 1997):

$$
k_{z}=\frac{4 \pi \Delta \theta}{\lambda \sin \theta} \approx \frac{4 \pi B_{\perp}}{\lambda \sin \theta}, \quad \text { radians } / \text { meter }
$$

where $\Delta \theta$ is the incidence angle difference between the two antennas as seen from the $\operatorname{target}, B$ is the spatial baseline between the two antennas, $h$ is the model forest height, $B_{\perp}$ is the normal baseline, $\lambda$ is wavelength of the radar system, and $\theta$ is the incidence angle from one of the antennas. Equation (1) shows that there is a direct relationship between the observed coherence and the structural properties of the scattering. In the most widely used representation of the RVoG model, the structure function is assumed to have an exponential shape (Papathanassiou and Cloude, 1997). However in the PCT approach, a Fourier-Legendre polynomial decomposition is proposed to describe the structure function, $f\left(z^{\prime}\right)$, in terms of known basis functions with unknown real coefficients.

It is important to notice that the structure function is bounded by the underlying ground phase and the vegetation height. Thus, it is critical to obtain good estimates of those elements prior to the profile estimation through the expanded FourierLegendre series. In the Legendre series development, $n$ baselines provide $2 n+1$ terms of the series. Therefore, in the simplest practical application, a single baseline solution can provide the second order of the scattering profile.. In this special single baseline case $(n=1)$, it allows determination of up to three terms of the series. The unknown coefficients $a_{i 0}$ (for the single baseline case) can then be estimated using a simple matrix inversion of equation (3):

$$
\left[\begin{array}{ccc}
1 & 0 & 0 \\
0 & -j f_{1} & 0 \\
0 & 0 & f_{2}
\end{array}\right]\left[\begin{array}{l}
a_{00} \\
a_{10} \\
a_{20}
\end{array}\right]=\left[\begin{array}{c}
1 \\
\operatorname{Im}\left(\tilde{\gamma}_{k}\right) \\
\operatorname{Re}\left(\tilde{\gamma}_{k}\right)-f_{0}
\end{array}\right]
$$

where $f_{i}$ represents the Legendre polynomial parameter at order $i, \quad \tilde{\gamma}_{k}$ represents the polarimetrically optimised complex coherence for baseline-dependent $k_{z}$, and $a_{n n}$ are the (real) Legendre coefficients. It should be noted that the $f_{i}$ terms are functions of the known quantities $k_{z} \cdot \mathrm{h}_{\mathrm{v}}$. The evaluation of these coefficients is solved as a matrix inversion problem. The equation can be inverted in a simple manner as shown in (4):

$$
[F] \underline{a}=\underline{g} \Rightarrow \underline{\hat{a}}=[F]^{-1} \underline{g}
$$

In the instance of two baselines, for instance, an improved vertical profile description at the second order is obtained by an expanded structure function now containing four unknown coefficients as shown in (5), where $P_{i}$ are the Legendre polynomials

$$
\hat{f}\left(z^{\prime}\right)=1+\hat{a}_{10} P_{1}\left(z^{\prime}\right)+\hat{a}_{20} P_{2}\left(z^{\prime}\right)+\hat{a}_{30} P_{3}\left(z^{\prime}\right)+\hat{a}_{40} P_{4}\left(z^{\prime}\right) .(5)
$$

The main purpose of this work is to determine the structure function using this PCT approach applied to data from a 'single-pass' polarimetric InSAR system. Single-pass in this context refers to a single baseline with rigidly connected antennas such that temporal decorrelation effects are absent from the data. Therefore (3) and (4) are relevant in this case.

\subsection{Tree Height and Ground Phase Estimation}

In this methodology, we use a 'boot-strapping' approach to obtain two of the unknown parameters, $h_{v}$ and $\phi$ for the initial canopy boundary estimates. The height and ground retrievals are obtained by the use of a modified RVoG model, where another parameter is added to compensate for the "underestimation" of the RVoG. For that purpose, (Treuhaft et al., 2000) considered a fixed extinction assigned empirically to the radar. The mean extinction parameter allows computation of the canopy thickness. The fixed extinction coefficient compensates for both density and structure variations (Papathanassiou et al., 2003). In this two-layer model, the observed coherence is given by the formula:

$$
\tilde{\gamma}(w)=e^{j \varphi_{0}} \frac{\tilde{\gamma}_{v}+\mu(w)}{1+\mu(w)}=e^{j \varphi_{0}}\left[\tilde{\gamma}_{v}+\frac{\mu(w)}{1+\mu(w)}\left(1-\tilde{\gamma}_{v}\right)\right],
$$

where $\varphi_{0}$ is the ground phase relative to the reference datum, $\gamma_{v}$ is the complex volume coherence and $\mu$ is the ratio of effective ground surface to volume scattering. $\tilde{\gamma}(w)$ refers to the normalized Fourier transform of the attenuated response from the vertical distribution of scatterers $(\mathrm{z})$ and $w$ represents the observed polarisation state. Equation (6) shows that by isolating the polarisation dependent terms $\mu(w)$, the resulting coherence lies in a straight line inside the complex coherence plane (Cloude et al., 2003).

In our study, the results of the inversion coming from the RVoG were used as bounds for the vertical profiles reconstruction, 
serving as the limits of the integrals in (1). Details of the derivation of ground phase and tree heights for that particular study could be found in (Mercer et al., 2011). The PCT profiles were calculated for slant range coherence images as transects in range and azimuth direction. The averaging window size for coherence calculation was 11 by 11 pixels in slant range coordinates.

\subsection{Biomass extraction}

A 'standard' operational method for direct biomass estimation is through the use of ground sampling sites as shown in equation (7).

$$
\text { Biomass }_{\text {forest }}=\rho \cdot\left(\frac{\pi}{4} \cdot D B H^{2}\right) \cdot f \cdot h \cdot N
$$

where stem Diameter at Breast Height (DBH), tree height (h), stem density $(\mathrm{N})$ and wood density $\rho\left[\mathrm{g} / \mathrm{cm}^{3}\right]$ are determined on site. The tree is modelled as a tapered cylinder (constant factor $\mathrm{f}$ ), leading to the stem biomass per unit area $\mathrm{B}$ [tons/ha]. Remote sensing methods often use an allometric relationship where some observable such as backscatter in the case of radar (Le Toan et al., 1992) is regressed against biomass estimates obtained from ground sample sites. Generally such methods become insensitive at biomass levels of about 150 tonnes/ha or greater. A more robust relationship has been shown to exist when tree height (as obtained from POLInSAR or lidar for instance) is the direct observable (Mette et al., 2004A; Mercer et al., 2009B). However the form of the allometric relationship seems to have species dependencies, and stimulates the interest in tomography which offers the potential to address the mixed species problem. The key idea here is to differentiate species by classification according to structure function. An allotropic approach with specific parameters would then be derived. In this paper we restrict ourselves to the first part of the problem derivation of the tomograms

\section{DESCRIPTION OF THE DATASET}

\subsection{Radar System}

The SAR data used in our study was collected during an airborne campaign (Mercer et al., 2009A, 2009B) carried out in winter 2008 in Alberta, Canada, near the town of Edson. A proof of concept design was built to accommodate and demonstrate the feasibility of an airborne PolInSAR system at L-Band by Intermap Technologies to recover tree height and ground surface elevation. The system was carried onboard an Aerocommander aircraft. Some of the system parameters are presented in Table 1:

\begin{tabular}{|c|c|c|}
\hline Central wavelength & 0.226 & $\mathrm{~m}$ \\
PRF/channel & 0.4 & $\mathrm{kw}$ \\
No. of channels & 12 & \\
Polarisation & full & quad \\
Horizontal baseline & 3.5 & $\mathrm{~m}$ \\
Flying altitude over ground & 1000 & $\mathrm{~m}$ \\
Azimuth resolution & 1.0 & $\mathrm{~m}$ \\
Slant range resolution & 1.1 & $\mathrm{~m}$ \\
\hline
\end{tabular}

Table 1: Design parameters of Intermap technologies' L-Band fully polarimetric InSAR radar system.
A quad-pol antenna pair supported by a rigid beam was mounted across track and provided a horizontal baseline of 3.5 meters. The flying height was around 1000 meters above ground level and ground resolution was close to 1.25 meters. The test altitude was chosen to obtain a satisfactorily large signal to noise ratio while also optimizing conditions for POLInSAR inversion (Cloude, 2006B).

\subsection{The Test Areas}

The particular test site (Mercer et al., 2009B) for generating the tomograms is a forested area near Edson, Alberta, Canada. It consists of densely forested areas interspersed with clearcut areas at various early stages of regrowth and with moderate variations of topography.. This test site was also chosen for availability of ancillary data such as airborne LiDAR and XBand generated digital terrain models, and is an effective candidate for biomass estimation of pine-lodged trees. Stand heights ranged from 10 to 30 meters. The forest stem density was estimated between 100 to $300 \mathrm{stems} / \mathrm{ha}$, based on high resolution photography analysis.

\section{RESULTS}

\subsection{Tomograms}

A composite polarimetric image (Pauli) of one of the passes is shown in Figure 1 with overlaid red lines indicating the location of particular tomographic profiles in the azimuth (along-track) and slant range (cross-track) directions. The green-colored texture is forest and the darker patches are the clearcut/regrowth areas. Figures 2 and 3 show the PCT profiles (tomograms) for these lines as indicated. The tomograms show clearly the distinction between clear cuts with low tree regrowth patterns, and older, 15-30 m canopy patches. The color scale represents the normalized structure function and should be a proxy for the internal backscattering intensity as a function of vertical location within the canopy. As explained in the above section, the upper and lower limits (tree tops and ground phase) are given from the RVoG inversion estimates which have accuracies of about 1-4 m (RMS) (Mercer et al., 2009B).

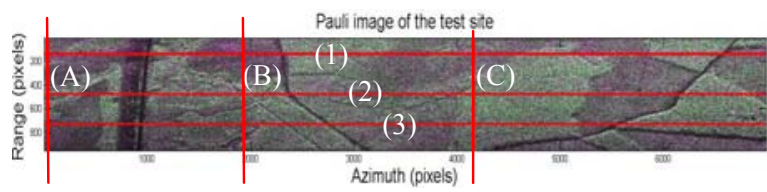

Figure 1: Pauli image and transects

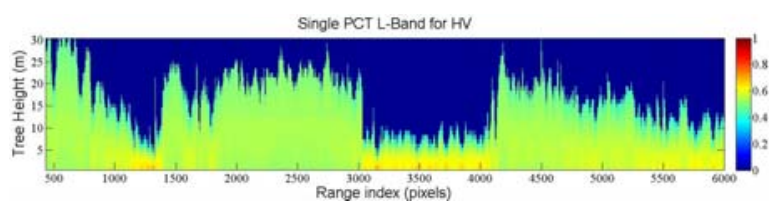

Figure 2a: Tomogram along Azimuth (1)

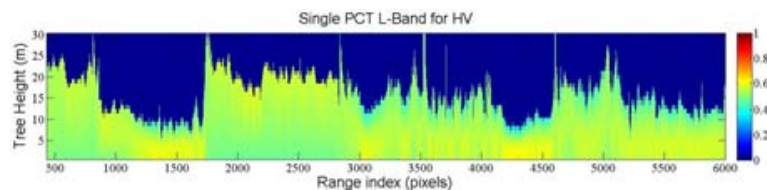

Figure 2b: Tomogram along Azimuth (2) 


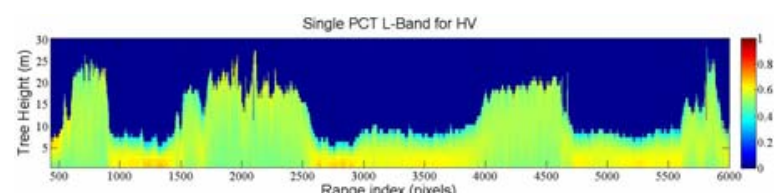

Figure 2c: Tomogram along Azimuth (3)

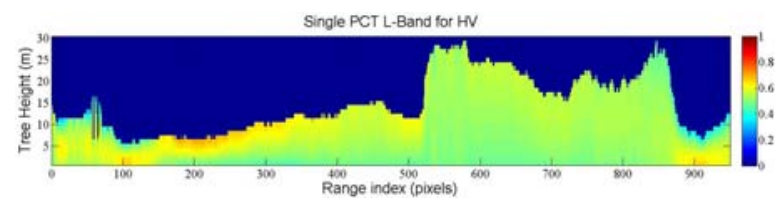

Figure 3a: Tomogram along Range (A)

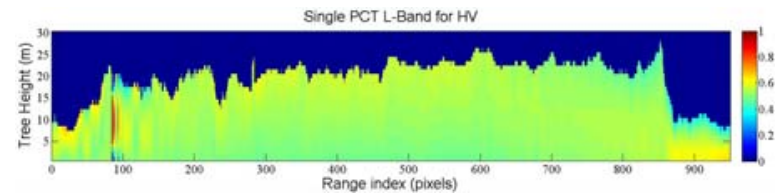

Figure 3b: Tomogram along Range (B)

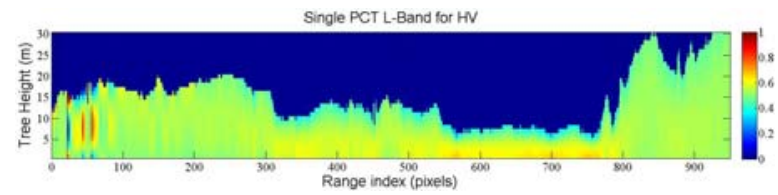

Figure 3c: Tomogram along Range (C)

The tomograms of the forested patches indicate scattering occurring relatively uniformly throughout the canopy. In contrast, the regrowth areas show more intense scattering from the ground area than the upper canopy. This may reflect the presence of more 'double-bounce' contributions from the lower portion of the canopy.

At this point there is no direct 'truth' with which to make a comparison of radar structure function. However it should be noted that the forest patches are relatively homogeneous such that it would be surprising to see large tomographic variations across this data set. A scene containing mixed species will be addressed shortly.

\section{CONCLUSIONS}

The worldwide destruction of forest as a source of $\mathrm{CO} 2$ emissions into the atmosphere is a major driver for attempts to determine the existing forest biomass content with increasing accuracy and spatial resolution. In previous work it has been shown that derivation of forest height using POLInSAR methods, together with use of an allotropic expression relating height to forest biomass could produce good results in the context of relatively homogeneous forests. In this paper we provide extensions to that work, utilizing a technique whereby 3D tomograms can be determined using a data set from an airborne, single-baseline, L-Band polarimetric InSAR system. The longer-term objective is to demonstrate that knowledge of the canopy structure function will allow for biomass differentiation in non-homogeneous forests. In this paper we show the first tomograms in the same forest area used for the previously noted biomass extraction. These examples show, qualitatively at least, that structural variation does occur even in the relatively homogeneous lodgepole pine forest test area being addressed.

Our study will be extended to various forest types in Canada and is expected to be applicable in various forest types over different tropical regions as well. Additionally, a novel dual baseline approach using the same system will be examined to determine if the expected improvement in structure function resolution can be achieved. Lastly, classification algorithms relating biomass to the structure function information will be developed and tested.

\section{ACKNOWLEDGMENTS}

The authors would like to acknowledge Alberta Innovates Technology Futures for funding this research. We are particularly grateful to Intermap Technologies Corp., Calgary, for providing the invaluable data and technical support.

\section{REFERENCES}

Bamler, R., 1997. Digital Terrain Models from Radar Interferometry, Photogrammetric Week, Stuttgart, Germany.

Cloude S.R, 2006A. Polarization Coherence Tomography. Radio Science. Vol.41, RS4017.

Cloude S.R, 2006B. Polarization Coherence Tomography, in Proceedings of 6th European SAR Conference, EUSAR 06, Dresden, May.

Cloude, S.R., 2009. Polarisation: Applications In Remote Sensing. Oxford University Press.

Dong J., Kaufmann k., Myneni R., Tucker C., Kauppi P., Liski J., Buermann W., Alexeyev V., Hughes M., 2003. Remote sensing estimates of boreal and temperate forest woody biomass: carbon pools, sources, and sinks. Remote Sensing of Environment, Vol.84, pp. 393-410.

Hajnsek I., Papathanassiou K.P., 2009. Tropical-ForestParameter Estimation by Means of POLinSAR: the INDREX-II Campaign. IEEE Transactions on Geosciences and remote Sensing, Vol 47, No.2.

Houghton, R.A., F. Hall, and S.J. Goetz. 2009. Importance of biomass in the global carbon cycle. Journal of Geophysical Research 114.

Leckie, D. G., and K. J. Ranson, 1998. Forestry applications using imaging radar. Principles and Applications of Imaging Radar, Vol. 2, 3d ed., Manual of Remote Sensing, F. M. Henderson and A. J. Lewis, Eds., John Wiley \& Sons, 435-509.

Lefsky M.A., Harding D.J., Keller M., Cohen W.B., Carabajal C.C., Del Bom Espirito-Santo F., Hunter M.O. and De Oliveira J.R., 2005. Estimates of forest canopy height and aboveground biomass using ICESat. Geophysical Research Letters, Vol. 32, L22S02.

Le Toan, T., Beaudoin, A., Riom, J. and Guyon, D., 1992 Relating Forest Biomass to SAR Data. IEEE Transactions on Geoscience and Remote Sensing, Vol. 30, No. 2, pp.403-411. 
Mercer, B., Zhang, Q., Schwaebisch, M., Denbina and M. Cloude S.R., 2009A. Forest height and ground topography at Lband from an experimental single-pass airborne POLInSAR system. Proceedings of the POLInSAR 2009 workshop, January 26-30, 2009. Frascaty, Rome, Italy.

Mercer, B., Zhang, Q., Schwaebisch, M. and Denbina, M., 2009B. 3D topography and forest recovery from an L-Band single-pass airborne POLInSAR system. IEEE International Geoscience and Remote Sensing Symposium, Cape Town, South Africa, pp. 33-36.

Mercer, B., Zhang, Q., Schwaebisch, M. and Denbina, M., 2011. Estimation of forest biomass from an airborne single-pass L-Band POLInSAR system. Proceedings of the POLInSAR 2011 workshop, Frascati, Italy. January 24-28.

Mette T., Papathanassiou K., Hajnsek I., Zimmermann R., 2003. Forest biomass estimation using polarimetric SAR interferometry. Proceedings of IEEE International Geoscience and Remote Sensing Symposium (IGARSS'03), Toulouse, France, July 21-25.

Mette T., Papathanassiou K., Hajnsek I., Pretzsch H., Biber P., 2004A. Applying a common allometric equation to convert forest height from POLInSAR data to forest biomass. Proceedings of IEEE International Geoscience and Remote Sensing Symposium (IGARSS'04), Anchorage, September 2024.

Mette T., Papathanassiou K. and Hajnsek I. 2004B. Biomass estimation from polarimetric SAR Interferometry over heterogeneous forest terrain. Proceedings of IEEE International Geoscience and Remote Sensing Symposium (IGARSS'04), Anchorage, September 20-24.

Papathanassiou, K. P., and Cloude, S.R., 1997. Polarimetric effects in repeat-pass SAR interferometry, Proceedings of IEEE International Geoscience and Remote Sensing Symposium (IGARSS'97). Vol. 4, pp. 1926-1928. August 3-8.

Papathanassiou, K. P., Cloude, S. R., 2003. A three stages Inversion Process for Polarimetric SAR Interferometry. IEEE Proceedings, Radar, Sonar and Navigation, Vol.150, No. 03, pp. 125-134.

Treuhaft R. N., Siqueria P., 2000. Vertical structure of vegetated land surfaces from interferometric and polarimetric radar, Radio Science, Vol. 35(1), pp 141-177.

The United Nation Development Group (UNDG), 2008. UNREDD Programme Fund Overview, http://www.undp.org/mdtf/un-redd/overview.shtml (accessed April, 29, 2010.

Revised April 2012 